\title{
Can Teachers Bridge the Theory-Practice Gap? An Ethnographic Study of a Teacher
}

\author{
Carmen Álvarez Álvarez \\ University of Cantabria, Santander, Spain
}

\begin{abstract}
In education, there has been a gulf between the production of pedagogical knowledge and the way that it is put into practice in education centres, popularly known as the theory-practice gap. This paper presents an approach to how teachers can bridge this gap so as to bring together both of these dimensions of education. It summarises an ethnographic case study carried out collaboratively with a Spanish teacher who has explored the relationship between theory and practice as part of his professional development along his life, and generated his own relationship model, which has been actively developed in the education establishment where he works. The conclusion of the paper includes some central ideas that are decisive in the processes of the relationship between theory and practice, which could be useful for any teacher who seriously seeks to link knowledge and action and promote their own coherence and the school improvement.
\end{abstract}

Keywords: theory-practice gap, teacher training, teacher development, coherence, school improvement

\section{Introduction}

In general terms, theory is understood as the result of academic production, the rationale and justification of practices backed by the proposals made by different authors or ideal educational situations. A great diversity exists in this regard. Practice can be understood as the act of teaching in education establishments, as the possible application of academic creation, or as what really happens in education. Therefore, a certain variety of meanings also exist.

In this paper, "theory" is understood to be pedagogical knowledge systematically developed by researchers and university academics. To refer to "theory", the term "knowledge", "science", or "research" will be used. "Practice" is understood to be the day-to-day work of teachers in education centres of different levels-from infant education to the university system-above all in classrooms, but also outside them. When used in this way, the term "practice" covers all the range of behaviours, actions, attitudes, and values shown by teachers in their places of work, and more specifically, in their classrooms. To refer to "practice", terms, such as "praxis", "action", and "teaching", are used. To sum up, "educational theory", then, is understood as formal knowledge produced about education, and "educational practice" as the teaching activity carried out in education establishments (Álvarez, 2013). Between these two dimensions of education, there is a gap, namely, a distance that is difficult to bridge due to its intrinsic complexity and historical evolution.

How did the theory-practice gap come about? There are many reasons for the theory-practice gap, and as stated by Klein (1992) in her research, the reasons are complex; they are interrelated, and not all of them are yet

Carmen Álvarez Álvarez, Ph.D., lecturer, Department of Education, University of Cantabria. 
known. Going to the past can we understand why present and future teachers have considered faculties of education to be too theoretical and far removed from the reality of teaching; and why, conversely, university academics have considered the teaching bodies to be fairly unreliable and their efforts and achievements not to be worthy of much respect (Allen, 2009; Álvarez, 2013; Broekkamp \& Hout-Wolters, 2007; Hennessy \& Deaney, 2009; Korthagen, 2007).

In Spain, in infant and primary education, originally there was no theory-practice gap, given that the first teachers did not have any pedagogical training and their knowledge came exclusively from their day-to-day teaching experience. There were no educational theories other than the common sense ones imposed by their own practice. In secondary education, initially, there was no theory-practice gap either, as the teachers' training was initially academic, as was their practice. Secondary schools fulfilled the social role of preparing-socially and culturally - a small select minority for university. It can therefore be stated that, originally, neither primary nor secondary school teachers were affected in any way by a distancing between theory and practice (Anguita, 1997; Rozada, 2007).

In Spain, as in other European countries, the gap appeared first in infant and primary education. The creation of teacher training institutions (Escuelas Normales) in 1838 can be taken as a milestone in the development of a specific theory for that purpose (Anguita, 1997; Rozada, 2007). The integration of teacher training in the university was a controversial subject, as teaching was considered to be a profession with little prestige, not requiring a high level of specialisation, and training for teachers was considered to have its own individual characteristics, not comparable to other forms of professional education (Anguita, 1997).

The dissemination of pedagogical and didactic knowledge in Spain was slow. In fact, it was possible to find teachers without a degree well into the 20th century; but at the same time, whilst it did not reach all people, a legitimised body of pedagogical knowledge was gradually being developed which was, in general, isolated from the practice of education. A theoretical field of knowledge about education was slowly created, mainly by people who were not involved in the practice of teaching in schools. In this way, the gap between theory and practice started to appear in the first levels.

In secondary schooling, the fault appeared earlier, basically produced as a consequence of a change in the traditional elitist education system to the technocratic education system for the masses, which took place half-way through the last century. Secondary schools changed from having a very select student body to one taken from the general population. This meant that the academic, disciplined-based knowledge of teachers started to be inadequate for the new situation (Escudero, 2009; Rozada, 2007).

What is the current status and development? The educational situation has become gradually more fragmented until it has reached its present status, whereby theory is generated mainly in the university, and practice is developed in educational establishments, moving in parallel, with little communication between them (Allen, 2009; Álvarez, 2013; Broekkamp \& Hout-Wolters, 2007; Gimeno, 1998; Klein, 1992). Ideally, universities and schools should be linked more closely, fostering the construction and dissemination of pedagogic knowledge that is profound, comprehensive, and open to complexity, but this is not always the case (Miretzky, 2007).

Theory and practice are most likely to come close, according to many researchers, in the initial period of teacher training, since students approach the most relevant pedagogical ideas in the field and at the time they do their teaching practices in schools, which allows them to grow both theoretically and practically (Allen, 2009; M. Cheng, Tang, \& A. Cheng, 2012; Korthagen, 2010). However, once this period has been completed, the 
relationships between theory and practice depend, above all, on teachers and their work context, which is particularly affected by the professional culture in the school. As shown by Klein (1992), the professional socialisation of teachers into school cultures generally brings scant incentives for the cultivation of intellectual issues by teachers, which allows the theory-practice gap to be maintained and consolidated further. In this regard, Klein (1992) considered the main problem to be the desire of academics and practitioners to maintain the status quo, which is more comfortable in education, requires little effort, and seems more secure than change, as well as the lack of stimuli for change.

In view of the above, it is difficult to make valid proposals to relate theory and practice for all teachers. Perhaps the first requirement that needs to be met is the desire on the part of teaching staff to bring both theory and practice into a closer relationship. The second one could be efforts to be made for change: undertaking permanent professional development, being self-critical about professional performance, and seeking to bring ideas and practices closer (Álvarez, 2013). Bringing theory and practice closer is not easy for a teacher, but it is certainly interesting to attempt to do so, as professional development is stimulated in the process.

In an attempt to shed light on the above issues, what follows recounts the contribution of José María Rozada Martínez, one of the professionals who has worked on this subject in Spain from both sides, both theoretical (as a lecturer at the University of Oviedo, Spain) and practical (as a primary school teacher at Germán Fernández Ramos State School).

This researcher and teacher proposes that, to overcome the theory-practice dichotomy, it is necessary to construct and recognise a "small pedagogy", that is, a space half-way between academic theorisation and teaching practice, fields that are currently rather far apart. In order to create these, he believes that a plane of theory and a plane of practice must be recognised which attract each other, instead of repelling each other. He proposes an intermediate theory and a practice between those previously formulated, which has been called "second-order" (see Figure 1) (Rozada, 2007).

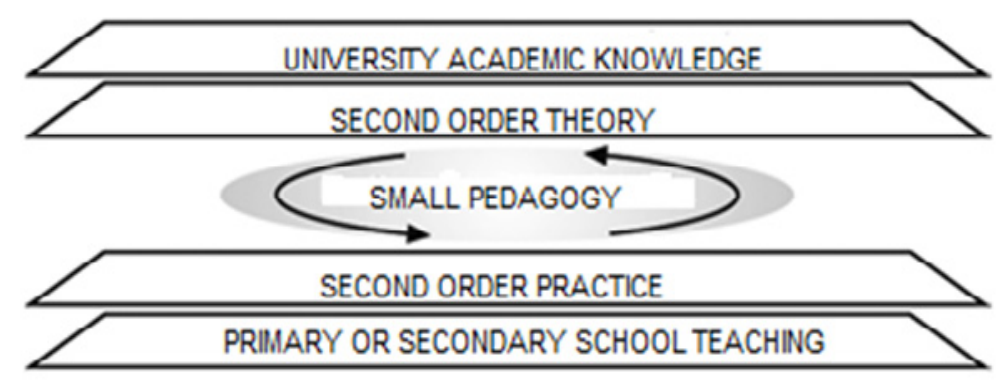

Figure 1. Relationship between theory and practice (Rozada, 2007).

Second-order theories, unlike university academic knowledge, permit dispersion, and therefore, forego specialisation. The assumption is that different theoretical contributions serve to feed and clarify knowledge to build the most complex professional thinking possible. These are committed to practice, where it is possible to identify a set of general, albeit somewhat disperse, principles (Rozada, 2007).

Second-order practice differs from school teaching in that it involves acknowledging that practices can be developed on the basis of approaches that go beyond common sense, thus, coming close to knowledge. In terms of the author's model, second-order practice is characterised by the reflection necessary to become aware of the ordinary thinking that guides teaching practices, a critical distancing from didactic traditions coming from the 
education establishment which shape the ways teachers do things in the classroom and in the centre. It is a practice that does not negate the classroom with all its complexity, but it involves at least taking a certain level of reflective distance (Rozada, 2007).

The relationship that a teacher can establish between the two second-order planes of theory and practice is what Rozada called "small pedagogy". It is a complex borderline territory, with many little-explored, two-way paths. Using these avenues, teachers perform their work at the same time ensure their professional training and create the conditions for self-emancipation.

Based on this approach, a piece of empirical research that explores the theory, practice, and their interrelationships in the practice of this "particular" researcher and teacher has been carried out, examining the four planes previously described. Before delving into the research, the methodological framework will be described.

\section{Methods}

In the research presented here, in order to empirically investigate the theory-practice relationships, a single case study was carried out by using an ethnographic methodology. Authors, such as Korthagen (2007), have emphasised the claim that educational research on the relationship between theory and practice must be done from an internal perspective. Others, such as Rockwell (2009), also argued that, from an ethnographic point of view, one of the main problems is the relationship between the teacher's knowledge and pedagogy.

Why a single case study? Because of the qualities that it presents. Stake (2005) stated that we study a case when it holds a special interest for us. Rodríguez, Gil, and García (1996) proposed that a single-case design is justified for three reasons:

1. Its critical nature, that is, the case allows us to confirm, change, modify, or broaden the knowledge about the object of study;

2. Its extreme or unique nature, that is, its unrepeatable, distinctive character;

3. Its revealing character, which occurs when the researcher has the opportunity to observe and analyse a phenomenon, situation, subject, or fact that was previously inaccessible to scientific investigation.

This case strictly complies with these requirements:

1. The case has a critical character, as the pedagogy developed by the teacher permits the confirmation, modification, and broadening of the knowledge of the theory-practice relationships in teaching.

2. Both the teacher and the classroom have a unique, peculiar nature.

The teacher, who worked at the Education Faculty of the University of Oviedo, Spain (Facultad de Ciencias de la Educación de la Universidad de Oviedo), developed a theoretical model about theory-practice relationships and published almost a hundred articles on pedagogy. He has been recognised in various academics spheres as an "authority", and has been invited to participate in various national education forums.

In his daily practice, the teacher tried to establish links with the educational theory that he had read throughout his professional career, acting as a researcher of his own practice in the classroom.

He was also involved in continuous training of teachers as an advisor in a teachers' centre, which he understood as a question of theory-practice relationships.

3. It reveals information about this phenomenon, which is still relatively unknown in education. Whilst there are some studies on the subject of the theory-practice relationship, it is still little known in the education science field. 
The research model used in this case study is that of school ethnography. In order to carry out ethnographic research, the researcher has to become submerged in the study of a community's culture and so understand the behaviour of the subjects who are part of it, sharing their lives, and thus, obtaining rich, first-hand knowledge (Rockwell, 2009). Ethnography applied to a school is called "school ethnography" and it calls for the researcher to live with the education agents in their natural context and environment: classrooms and centres. To collect data, the ethnographer employs qualitative data collection techniques, the most important being participant observation, followed by interviews and discussion forums. To ensure the reliability of the data, four basic strategies were used: data contextualisation, data saturation, negotiation of the progress reports with those involved, and the triangulation of time, techniques, and informants.

This study attempted to answer the question: How does Rozada relate theory and practice in education? The researcher attended the classes taught by this teacher (primary education, year 6) for a whole school year at a state school and had direct contact with the education community of the school. This teacher has spent more than 30 years studying theory-practice relationships, publishing and designing innovative ways of teaching, and promoting conscious relationships between educational knowledge and school practice.

The ethnographic methodology took place in the observed classroom, but it also incorporated the school community, with the aim of verifying the teacher's theory-practice relationships and of understanding how they were promoted. In this article, it is merely possible to show a small part of the data collected, due to their density and to the actual purpose of the paper.

As the data to be analysed are qualitative in nature, two basic strategies were used:

1. Interpretation, which permitted the description of the context and the interactions occurred in the teaching-learning process, and the creation of the links between theory and practice and the teacher's theoretical approaches;

2. Analysis of the content, which permitted the categorisation and systematic, in-depth understanding of the discourse of the different members of the education community, in order to make valid inferences about the data collected.

From Rozada's four-plane model, two levels of analysis were established: (a) a separate review of the four planes around his teaching work and the partial interrelationships produced between them; and (b) an inductive and deductive review of the two intermediate planes, to assess the two-way paths identified in "small pedagogy".

\section{Results}

Every teacher concerned about that teaching will have wondered at one time or another about the theory-practice relationship, and the most committed ones will have tried to address the issue during their teaching career. Rozada is one of those teachers, since he has made an effort throughout his life's work in education to link academic knowledge and classroom teaching, with passion and courage.

Rozada started teaching when he was 18 years old and worked as a teacher until he was in his sixties, when he took early retirement. Throughout his life, he had also worked as a collaborating professor in the Geography Department of Oviedo University (six years), as an advisor at a Teachers and Resources Centre (14 years), and as a teacher in the area of didactics and school organisation in the Education Department at Oviedo University (16 years).

In his long career, he permanently dealt with the theory-practice gap, trying to establish a relationship between education knowledge and school action. At least five aspects can highlighted as having been central in 
the process. These have been organised in such a way as to be closely related to the four-plane model previously described, as created by him:

(a) The cultivation of academic training and reading (higher plane);

(b) A self-critical review of the professional and institutional traditions and cultures (lower plane);

(c) The creation of a personal second-order theory (upper-intermediate plane);

(d) The creation of a personal second-order practice (lower-intermediate plane);

(e) The construction of a small pedagogy (occupying the space between second-order theory and second-order practice).

The bridging of the theory-practice gap is always a delicate question in which no simple recipes for success exist; however, the ideas collected below are basic elements in the process for this particular teacher, as they can also be for teachers who wish to use them. In the results section, this will be discussed further, including ideas that are key to the process and how they were addressed in the case study.

\section{Cultivating Academic Training and Reading}

One of the possibilities that teachers have for starting a process of relating theory and practice is the cultivation of academic training and reading as part of their professional development. This aspect is reflected in the academic/university knowledge plane in the model. Academic training and reading enable teachers to explore previously unknown educational areas, helping to shape their thinking and inform their practice (Day, 2005). It would be interesting for teachers to be become involved in an academic self-learning and personal reading process. Only in this way can teachers outline and define their theoretical propositions. Gimeno (1998) stated that common sense is transformed by coming into contact with formal knowledge. Formal knowledge illustrates and helps to provide norms and principles, as well as to break professional routines.

For Rozada, the above is a crucial aspect, which has led him to be very concerned about his own training in education, and to devise his own theory of pedagogy. When the researcher asked him about his academic theory, he stated that it was shaped on the basis of:

1. All, or almost all, his reading, which has been referenced in the bibliography of his publications, although he has read hundreds of books that were not referenced. The key areas on which he focused were didactics of social sciences, general didactics, curriculum theory, theory-practice relationships, critical pedagogy, constructivist psychology, action research, school organisation, amongst others;

2. Attending lectures, independent of their quality. His main subjects of interest were the degree of institutionalisation of universities and the estrangement of the kind of education being discussed from the actual practice and experience of classroom education. Rozada studied education and also holds a degree in geography and history;

3. Attending various academic events: courses, Ph.D. viva voce examinations, examinations to obtain teaching positions, conferences, congresses, etc..

\section{Self-critical Review of School Traditions}

Another central element for teachers is their professional practice, or their practical experience. It is undeniable that there is a school practical reality, historically, socially, and institutionally constructed and consolidated, built on very powerful traditions, which is difficult to question and can only be escaped by those who are not engaged in teaching. This is closely related to the plane of "primary or secondary school practice" in the "small pedagogy" model. 
This reality needs to be lived, but also questioned, subjecting it to self-criticism and initiating alternative practices, in order to prevent it from only being fed by traditions. Teaching experience is, without doubt, a fundamental component in the professional development process of teachers. When a new teacher starts in the teaching profession, they often feel as if they are in a state of shock with their practice (Allen, 2009; Orland-Barak \& Yinon, 2007), as they do not know how to face the reality of day-to-day school life.

Rozada, as a teaching professional, took this issue seriously and developed a process of action research in which he thoroughly reviewed his educational practices:

1. Making audio and video recordings of his classes, by analyzing them, he can understand better what happened in his classes, self-critically questioning the least successful ways of doing things, firmly resolved to change them, reflect on them, look for alternatives, and put them into practice;

2. Writing reflective diaries on his classes to become aware of the best aspects of his classes, as well as those that needed improvement;

3. Introducing external observers into the classroom (student teachers and those on teaching practices, work colleagues or researchers) to provide him with a complementary view to his own that would serve to stimulate improvement.

\section{Creating a Second-Order Theory}

The third element that can be recognised in teachers is the creation of a second-order theory, namely, the systematisation of their own pedagogical thinking - the conscious construction of their own way of thinking. Teachers are reflective, rational subjects, who make decisions, judgements, etc., and whose thoughts guide and orientate their conduct (Clandinin, 1995). The research into teachers' thinking and personal practical knowledge has been concerned with the reasoning processes that occur in the mind of teachers in the planning, development, innovation, and evaluation processes of their professional activity. Their relevance to establish theory-practice relationships has been highlighted to the extent that they enable a systematic review of teachers' own thinking processes.

In the case of Rozada, this was done by means of:

(a) Publications, including books, chapters in co-written books, and more than 80 articles published in journals (all of them in Spanish);

(b) Unpublished documents, such as his teaching projects, where he synthesised his pedagogical principles, and which were specifically conceived to develop a coherent practice-theory line of action;

(c) Oral discussions: university lectures, various courses, presentations, talks, etc..

\section{Creating a Second-Order Practice}

The fourth basic element for Rozada in the process of bridging the theory-practice gap is the creation of a second-order practice, that is, a personal way of teaching, fed by reflective experience and individual pedagogical thinking, taking distance from conventional ways of teaching.

There are many educational practices that a teacher can develop, but if teachers intend to be consistent with their principles, innovation in both classrooms and centres is necessary. This should be real innovation, in the sense that it should be based on ideas, rather than merely improvised or spontaneous.

Rozada created his own second-order practices by:

1. Developing his own teaching-learning methodology based on dialogue, converting day-to-day teaching into an open forum in which students' contributions were always welcome, and trying to make education a 
space in which to develop critical thinking;

2. Creating his own teaching programme for the Asturian culture area, called Manolo and Vanina, a set of short-stories aimed at exploring traditional and current Asturian life; and using a values education programme, The Adventure of Life (La Aventura de la Vida), which provides very useful material to work on the education goals sought by the teacher;

3. Affirming community relations by coordinating the school Opening Project, the organisation and development of the "family school", the opening of the library during play-time, and the creation and coordination of reading clubs outside school hours (one for students and one for adults, both families and teachers).

\section{Constructing a "Small Pedagogy"}

Teachers should create a way of working based on didactic principles, connecting their theories and second-order practice in a coherent line by bringing down their ideas (academic training and reading) to feed their didactic principles and by raising their practices (self-critically reviewing their teaching experience), thus, creating their own theory and practice that are permanently related to each other.

Throughout the four previous sections, a particular way of bridging the theory-practice gap by a teacher has been reported, describing how he worked to overcome the gulf. An overall picture describing four ways of facing the theory-practice gap has been provided, in line with Rozada's theoretical model, which points to the existence of a small pedagogy, a professional way of thinking and living teaching, helped by self-learning and self-criticism, tirelessly seeking coherence between personal educational discourses and teaching practices.

It could be argued that this way of working is constructed in the space between the planes of second-order theory and practice (which planes in turn are informed by processes of self-learning and self-criticism), and between very different types of interactions (didactic principles, professional ideas, the teachers' thinking, innovative processes, etc.). Drawing on all the matters previously covered, Rozada constructed his small pedagogy by reflecting on theory and practice and trying to bring them together in a coherent way, even by collecting them all together in writing.

In this study, his first- and second- order theories and practices have been delved into, and a deductive and inductive analysis has been carried out. This has revealed an extraordinary coherence between the desires and the facts in the daily life of both the classroom and the centre, although not without difficulties that preclude the identification of wishes and reality. Besides, the educational community of his primary education centre were involved in the research. They showed great satisfaction with the theories and practices of their teacher and reaffirmed the existence of a way of thinking and acting that is uncommon, highly advanced and very positive. This is very interesting from the point of teaching quality, as it entails acknowledging that teachers have primary responsibility for their own professional development.

\section{Discussion}

The discussion is organised around the same areas as the results. The relevance of this level of theory-practice relationship will be argued, and the consequences of the absence of its permanent cultivation will be discussed.

\section{Cultivating Academic Training and Reading}

The habit of academic training and reading, in any of their manifestations, places teachers at the doors of 
knowledge, and gives them the opportunity to improve their understanding of education (Korthagen, 2010; Miretzky, 2007). It is not possible to relate theory and practice if one of the two is lacking. For teachers to bridge the theory-practice gap and become true teaching professionals, they should carry out further study on education and take steps towards the theoretical mastery of their field.

One of the most unfortunate consequences of not cultivating academic training is the general professional alienation of teachers (Giroux, Freire, Arias, \& McLaren, 1990). This means that teachers engage in teaching without having a perfect grasp of the basic theories of their work. In their initial training, they superficially studied some educational theories, but in such a way that they will have not consciously taken on board the profound implications of their role as teachers in fighting the reproduction of the inequalities that the school system perpetuates. Only a profound and ongoing process of academic training and reading by teachers can contribute to overcoming this situation (Álvarez, 2013; Korthagen, 2007).

\section{Self-critically Reviewing Scholastic Traditions}

The relevance of reviewing one's own practice has been highlighted by different authors for some time now. Ancess, Barnett, and Allen (2007) considered that research into practice brought about insights into school practices and education reform processes. Rathgen (2006) and Tripp and Rich (2012) defended the relevance of analysing classroom recordings due to their potential for teachers and professionals. Authors linked to action research have also advised of the usefulness of a teacher who is also a researcher into their own practice, in order to overcome problematic situations where there is room for improvement, which need an urgent, practical answer to a problem. They claimed that, in the process, teachers hone their professional judgment, accept responsibility, and restore their dignity, thus, freeing themselves. The only requirement needed to start this process is for teachers to truly want to improve their teaching and grow as professionals. A pre-requirement for action research is a need being felt by practitioners to initiate change, innovate, and improve (Korthagen, 2007).

A fundamental part of the construction process of the professional teacher resides, without a doubt, in classroom experience. But teaching experience by itself is a very limited training tool that could cause some problems, such as the fact that habits and routines may never be called into question. School practice is all-absorbing and needs to be revised, so that it does not degenerate into a mere repetition of poorly substantiated practices.

By definition, the pace of teaching is fast, and in teaching activities, it is necessary to make hundreds of decisions every hour of every class, in such a way that the teacher does not have time to think deeply about each action. This means that teachers need to find a space to examine and develop their own values as expressed in day-to-day classroom work (Hennessy \& Deaney, 2009; Rockwell, 2009). Unless time is apportioned to the self-critical review of one's own practice, it is not possible to bridge the theory-practice gap, because many of the angles of the multi-faceted, daily classroom and school practices remain unknown.

\section{Creating a Second-Order Theory}

Authors, such as Clandinin (1995), have stated that the study of the teacher's way of thinking is the ideal method to establish links between knowledge and action. The writing and the dissemination of one's ideas are, without a doubt, important stimuli to systematise the teacher's individual way of thinking. Again, attention should be drawn to the uniqueness of the case explored, as it is uncommon to find such a teacher, at least in Spain, given that the majority of primary school teachers do not read very much on pedagogy and do not 
maintain their own training at the forefront of their professional performance. Neither do they write or publish about education on a regular basis, which in itself produces a vacuum in pedagogic thinking from the point of view of the organisation of their own ideas. Scientific knowledge about education can give rise to well-grounded school practices by constructing procedural principles, which implies a greater reflective role of educators in their work (Postholm, 2008). Defining and redefining their own didactic principles in light of the cultivation of academic training is a way of bridging the theory-practice gap available to any teacher who seeks to do so.

This does not mean that they need to become compulsive consumers of didactic research. Basically, the proposal is that there is a need for teachers to have a relationship with teaching theory, and rethink it; this can be accomplished by trying to take ideas to help define a consistent framework of action in teaching, thus, becoming endowed with patterns of thought and knowledge with which to organise and interpret their daily action (Cochran-Smith \& Lytle, 2009).

\section{Creating a Second-Order Practice}

These questions imply a significant change with respect to the traditional ways of doing things in classrooms and education centres. They involve working in an innovative way, with initiative and passion; following guidelines based on the education sciences, both in everyday work in the classroom and outside of it; and staying away from those practices that have become settled and are being reproduced in the day-to-day life of the school. It is not the same to address the challenges of teaching practice with no theoretical input, merely following the inertia of non-reflective practice, as to address them on the basis of elaborate theoretical knowledge. Academic knowledge should inform and guide didactic action.

The lack of an innovative practice seated in scientific didactic ideas condemns the school experience to routine and to the reproduction of stereotypical answers. The majority of teachers, after some years of work, rapidly develop resistance to change and inertia, reproducing in this way an unenlightened school culture, based on stereotypical responses, subjective beliefs, dominant ideology, and prejudices (Klein, 1992; Korthagen, 2010).

\section{Conclusion}

Despite the difficulties, it cannot be said that it is impossible to relate educational theory and practice. As one investigates the overall subject, everything seems to suggest that relationships between knowledge and action are possible, but are usually diffuse, complex, and complicated.

Nevertheless, it is noteworthy that teachers are at the centre of the relation between theory and practice in education. The minds of teachers are engaged in organising their thinking, their academic knowledge, and their actions, and in the process, it is feasible to build relationships between theory and practice.

Some conclusions can be made from the analysis of how Rozada faced the theory-practice gap, with respect to how the teaching body in general can also do so, overcoming many of the limitations that the theoretical exploration of the state of affairs has allowed us to show. They point to cultivating self-learning and self-criticism, constructing professional beliefs, innovating, and committing to one's coherence.

In many cases, teachers' experience makes them more resistant, converting them into routine subjects who may have many years of service in education, but basically may be repeating the same schemes learned at the beginning of their professional career. They have integrated ways of doing that they believe work for them and 
have not constructed their own thinking as teaching professionals. In this way, the theory-practice gap becomes something very problematic, to the extent that it is possible to speak of professional alienation.

Nowadays, a good part of the experienced teaching body reject their academic training and call themselves "university-of-life, down-to-earth teachers". There are more than a few cases of practising teachers who have refused to read books on pedagogy once their initial training has finished, and this brings us to another problem, namely, that when teachers in infant, primary, or secondary education have intellectual concerns, sooner or later, they move to the university to cultivate this dimension, and the school loses someone who would surely bring valuable observations and experiences. This is an unsolved problem that has important effects on the future development of teachers (Day, 2005).

How can the theory-practice gap be bridged by teachers? In terms of this study, it can be said that by cultivating academic training and reading, self-critically analysing the teaching experience, and creating personal second-order theories and practices in such a way as to construct "small pedagogy". And how is this achieved? By studying, reflecting, and acting, all of which must take place together, something that demands effort, passion, and courage.

Building a small pedagogy is a long process of building bridges between theory and practice, and it cannot be achieved overnight (Hennessy \& Deaney, 2009). However, it is certainly interesting to attempt to do so, as it places the subject in a positive position with respect to learning, training, the definition of professional principles, and innovation.

\section{References}

Allen, J. (2009). Valuing practice over theory: How beginning teachers re-orient their practice in the transition from the university to the workplace. Teaching and Teacher Education, 25, 647-654.

Álvarez, C. (2013). Enseñanza y desarrollo profesional docente. Pensar y vivir la educación (Teaching and teacher professional development. To think and to live the education). Madrid: La Muralla.

Ancess, J., Barnett, E., \& Allen, D. (2007). Using research to inform the practice of teachers, schools, and school reform organizations. Theory Into Practice, 46(4), 325-333.

Anguita, R. (1997). Algunas claves de la historia de la formación del profesorado en España para comprender el presente (Some key of the history of teacher training in Spain to understand the present). Revista Interuniversitaria de Formación del Profesorado, 30, 97-109.

Broekkamp, H., \& Hout-Wolters, B. (2007). The gap between educational research and practice: A literature review, symposium, and questionnaire. Educational Research and Evaluation, 13(3), 203-220.

Cheng, M., Tang, S., \& Cheng, A. (2012). Practicalising theoretical knowledge in student teacher's professional learning in initial teacher education. Teaching and Teacher Education, 28, 781-790.

Clandinin, J. (1995). Teacher's professional knowledge. New York, N.Y.: Teachers College Press.

Cochran-Smith, M., \& Lytle, S. (2009). Inquiry as stance: Practitioner research for the next generation. New York, N.Y.: Teachers College Press.

Day, C. (2005). Developing teachers: The challenges of lifelong learning. London: Falmer Press.

Escudero, J. M. (2009). La formación del profesorado de educación secundaria: Contenidos y aprendizajes docents (Teacher training for secondary education: Content and teachers learning). Revista de Educación, 350, 79-103.

Gimeno, J. (1998). Poderes inestables en educación (Unstable powers in education). Madrid: Morata.

Giroux, H. A., Freire, P., Arias, I., \& McLaren, P. (1990). Teachers as intellectuals toward a critical pedagogy of learning. London: Bergin and Garvey.

Hennessy, S., \& Deaney, R. (2009). "Intermediate theory" building: Intergrating multiple teacher and researcher perspectives through in-dept video análisis of pedagogic strategies. Teacher College Record, 111(7), 1753-1795.

Klein, M. (1992). A perspective on the gap between curriculum theory and practice. Theory Into Practice, 31(1), 191-197.

Korthagen, F. (2007). The gap between research and practice revisited. Educational Research and Evaluation, 13(3), 303-310. 
Korthagen, F. (2010). La práctica, la teoría y la persona en la formación del profesorado (The practice, theory, and individual teacher training). Revista Interuniversitaria de Formación del Profesorado, 68(24/2), 83-102.

Miretzky, D. (2007). A view of research from practice: Voices of teachers. Theory Into practice, 46(4), 272-280.

Orland-Barak, L., \& Yinon, H. (2007). When theory meets practice: What student teachers learn from guided reflection on their own classroom discourse. Teaching and Teacher Education, 23, 957-969.

Postholm, M. B. (2008). Teachers developing practice: Reflection as key activity. Teaching and Teacher Education, 24, 1771-1728.

Rathgen, E. (2006). In the voice of teachers: The promise and challenger of participating in classroom-based research for teachers" professional learning. Teaching and Teacher Education, 22, 580-591.

Rockwell, E. (2009). La experiencia etnográfica: Historia y cultura en los procesos educativos (The ethnographic experience: History and culture in education processes). Buenos Aires: Paidós.

Rodríguez, G., Gil, J., \& García, E. (1996). Metodología de la investigación cualitativa (Qualitative research methodology). Málaga: Aljibe.

Rozada, J. M. (2007). Son posibles los puentes entre la teoría y la práctica por todo el mundo demandados, sin pilares intermedios? (Are possible bridges between theory and practice throughout the defendants world, without intermediate pillars?). In J. Romero, \& A. Luis (Eds.), La formación del profesorado a la luz de una profesionalidad democrática (Teacher training at the light of a democratic professionalism) (pp. 47-53). Santander: Consejería de Educación.

Stake, R. E. (2005). The art of case study research. Thousand Oaks, C.A.: Sage.

Tripp, T., \& Rich, P. (2012). The influence of video analysis on the process of teacher change. Teaching and Teacher Education, 28, 728-739. 